Review article

\title{
Therapeutic potential of rice-derived polyphenols on obesity-related oxidative stress and inflammation
}

\author{
Esther T. Callcott ${ }^{\mathrm{a}}$, Abishek B. Santhakumar ${ }^{\mathrm{a}, *}$, Jixun Luo ${ }^{\mathrm{b}}$, Christopher L. Blanchard ${ }^{\mathrm{a}}$ \\ a Australian Research Council (ARC) Industrial Transformation Training Centre (ITTC) for Functional Grains, Graham Centre for Agricultural Innovation, Charles \\ Sturt University, Wagga Wagga, New South Wales, 2650, Australia \\ ${ }^{\mathrm{b}}$ New South Wales Department of Primary Industries, Yanco Agricultural Institute, Yanco, New South Wales, Australia
}

\section{A R T I C L E I N F O}

\section{Article history:}

Received 16 November 2017

Received in revised form 12 February 2018

Accepted 9 March 2018

Available online 20 March 2018

\section{Keywords:}

Obesity

Polyphenol

Rice

Oxidative stress

Inflammation

\begin{abstract}
A B S T R A C T
Global obesity rates are of epidemic proportion. With limited treatments available there is a large demand for therapeutic alternatives. Polyphenols derived from coloured rice varieties may serve as a potential functional food alternative in combating obesity and obesity-related diseases. The antioxidant and anti-inflammatory properties of polyphenols found in coloured rice varieties could have the ability to neutralize oxidative stress and modulate inflammatory responses in obese populations. This review discusses polyphenols derived from rice, the oxidative stress and inflammatory pathways involved in obesity pathogenesis, bioavailability of polyphenols and the therapeutic potential of polyphenols on transcriptional and molecular pathways related to obesity and obesity-related diseases.
\end{abstract}

(c) 2018 Faculty of Health and Social Sciences, University of South Bohemia in Ceske Budejovice. Published by Elsevier Sp. z o.o. All rights reserved.

\section{Introduction}

Metabolic Syndrome is a multifactorial disorder that develops through the interaction of several risk factors such as hyperglycemia, dyslipidemia, and hypertension (Huang, 2009). In conjunction to the aforementioned risk factors, obesity is the central and fundamental component to the development of this syndrome (Visioli, 2016). Obesity is the accumulation of abdominal adipose tissue resulting in an increase in the waist-hip ratio (Emdin et al., 2017). The WHO (2015), characterizes individuals who have a Body Mass Index (BMI) equal to or greater than 25 as overweight and a BMI equal to or greater than 30 as obese. Due to the exponential increase in obesity rates at epidemic proportions in developed countries, the process of adipogenesis and its transcriptional and physiological mechanisms have become a focal point in medical science (Salvado et al., 2015). Obesity manifests through multiple factors including genetics, environment, nutrition and level of physical activity (Rippe et al., 1998). In particular, studies have demonstrated obese individuals to have higher baseline profiles of inflammation and oxidative stress (OS) (Huang et al., 2015; Keaney et al., 2003).

Obesity has been significantly correlated with the development of other diseases including Type II diabetes mellitus (T2DM), cardiovascular disease, hypertension, a majority of cancers, asthma, chronic back pain, osteoarthritis and gall bladder disease (Guh et al., 2009). Healthier lifestyle choices are not always effective in combating obesity. Therefore, to overcome the obesity epidemic, therapeutic treatments are required, however, there are limited pharmaceutical treatments for obesity. A majority of drug treatments have been unsuccessful due to adverse side effects questioning safety concerns, thereby creating a high demand for alternative therapeutic options (Kakkar and Dahiya, 2015). The

Abbreviations: 5-LOX, 5-lipooxygenase; ADP, Adenosine diphosphate; ATP, Adenosine triphosphate; AT, Adipose tissue; BRE, Black rice extract; BMI, Body Mass Index; CAT, Catalase; C-3-G, Cyanidin-3-glucoside; DW, Dry weight; FFA's, Free fatty acids; HDL, High density lipoprotein; HFD, High fat diet; HSD, High sugar diet; IL-6, Interleukin-6; IкK $\alpha / \beta$, Inhibitor-kappa kinase $\alpha / \beta$; LDL, Low density lipoprotein; MSC's, Mesenchymal stem cells; MAPKs, Mitogen activated protein kinases; MCP-1, Monocyte chemotactic protein-1; ND, Not detected; NADH, Nicotinamide adenine dinucleotide; NF-кB, Nuclear factor kappa-B; IкB, Nuclear factor kappa light polypeptide gene-alpha; OS, Oxidative stress; ox-LDL, Oxidised low density lipoprotein; P-3-G, peonidin-3-glucoside; H+, Proton; ROS, Reactive oxygen species; RNS, Reactive nitrogen species; RE, Rice extract; SFA's, Saturated fatty acids; SOD, Superoxide dismutase; TLR4, Toll-like receptor-4; TPC, Total phenolic content; TCA, Tricarboxylic acid; TNF- $\alpha$, Tumour necrosis factor alpha; T2DM, Type II Diabetes Mellitus; Ub, Ubiquination.

* Author for correspondence: Charles Sturt University, ARC ITTC for Functional Grains, School of Biomedical Sciences, Locked Bag 588, Bldg. 288, Room 238, Wagga Wagga, New South Wales, 2650, Australia.

E-mail address: asanthakumar@csu.edu.au (A.B. Santhakumar). 
incorporation of functional foods with bioactive properties into diets may serve as a potential complementary alternative for obesity treatment.

Rice (Oryza Sativa L.) is a staple food consumed at least once a day by more than half of the world's population and is cultivated in over 100 countries (Mohanty, 2013). Specifically, coloured rice varieties have been demonstrated to possess anti-inflammatory (Candiracci et al., 2014) and antioxidant properties (Sangkitikomol et al., 2010) thus presenting rice as a potential candidate for nutraceutical and/or functional food alternatives. In particular, red and black coloured wholegrain rice varieties have been demonstrated to have therapeutic characteristics that have been attributed to the presence of polyphenols.

Polyphenols are a subclass of phytochemicals that are predominant in grains, fruits, and vegetables (Santhakumar et al., 2014). Incorporation of polyphenols into diets through rice consumption could be a potential solution for reducing the incidence of metabolic syndrome and its associated risk factors such as obesity. Therefore, it is fundamental for rice breeding programs to develop rice cultivars that not only appeal to consumers in taste and texture attributes but are also enriched with polyphenols with potentially elevated antioxidant and antiinflammatory capacity. It is also critical to highlight to healthconscious consumers that grains, when consumed as wholegrains, can serve as functional foods to meet their culinary and nutritional needs. This review aims to focus on the antioxidant, anti-inflammatory and anti-dyslipidaemic mechanisms of action by which rice-derived polyphenols could potentially modulate risks factors attributed to the development of obesity-related OS and inflammation.

\section{Polyphenols in rice}

Polyphenols are the most widely occurring groups of compounds and assist plants with essential functions such as growth and reproduction, disease resistance and pigmentation (Balasundram et al., 2006). There are multiple parameters that can affect the phenolic content in different rice varieties such as climate, soil conditions, genetics and farming practices (Goufo and Trindade, 2017) hence making it extremely difficult to pinpoint the exact phenolic composition of each rice variety.
Rice consists of different layers, the outer layer, generally termed the hull constitutes between 16 and $28 \%$ of paddy rice weight (Corke, 2015). During a process called de-hulling, the hull is removed to expose the bran. The resultant product is generally known as wholegrain rice. Wholegrain rice is the endosperm (white rice) with the bran layers still intact (Kealey and Clampett, 2000). The bran is comprised of several layers (the pericarp, seed coat, nucellus and aleurone layers), which constitutes $6-7 \%$ of the total paddy rice weight (Fig. 1) (Chen et al., 1998). It is in these ectopic layers of the endosperm that a large majority of the polyphenols resides. Polyphenols exist in both soluble and insoluble forms, with the soluble form accounting for $38-66 \%$ of the phenolic compound content in light brown rice varieties to approximately $81 \%$ of the phenolic compound content in red and black rice varieties (Adom and Liu, 2002; de Mira et al., 2009). Table 1 demonstrates the soluble and insoluble polyphenol composition found in wholegrain pigmented and non-pigmented rice varieties.

\section{Phenolic acids}

At least twenty-nine different phenolic acids have been identified in rice with ferulic acid (56-77\%), p-coumaric acid ( $8-24 \%)$ and sinapic acid (2-12\%) being the most abundant (Goufo and Trindade, 2017). Overall, phenolic acids in rice are comprised of $61-89 \%$ hydroxycinnamic acids and $12-28 \%$ hydroxybenzoic acids (Goufo et al., 2014). Furthermore, insoluble phenolic acids comprise $51 \%$ of the total phenolic content (TPC) in bran and $61 \%$ of the total TPC in whole-grain rice. Studies have shown that brown rice varieties have higher levels of ferulic acid and $p$-coumaric acid when compared to the same varieties polished to white rice (Butsat and Siriamornpun, 2010; Zhou et al., 2004), suggesting that a large majority of phenolic acids are retained in the rice bran. In pigmented rice varieties, the global average of soluble TPC has been reported to be two to three times higher than the insoluble TPC in bran and whole-grain. However, the studies that reported these findings used extraction solutions containing methanol combined with hydrochloric acid to ascertain soluble phenolic acids (Tuncel and Yilmaz, 2011; Zhang et al., 2010). Hence, using aqueous mixtures containing alcohol and acid may facilitate in potential insoluble phenolics being released due to the acid addition, thus presenting results with higher soluble TPC compared to other studies (Goufo and Trindade, 2014; Wrolstad et al., 2005).

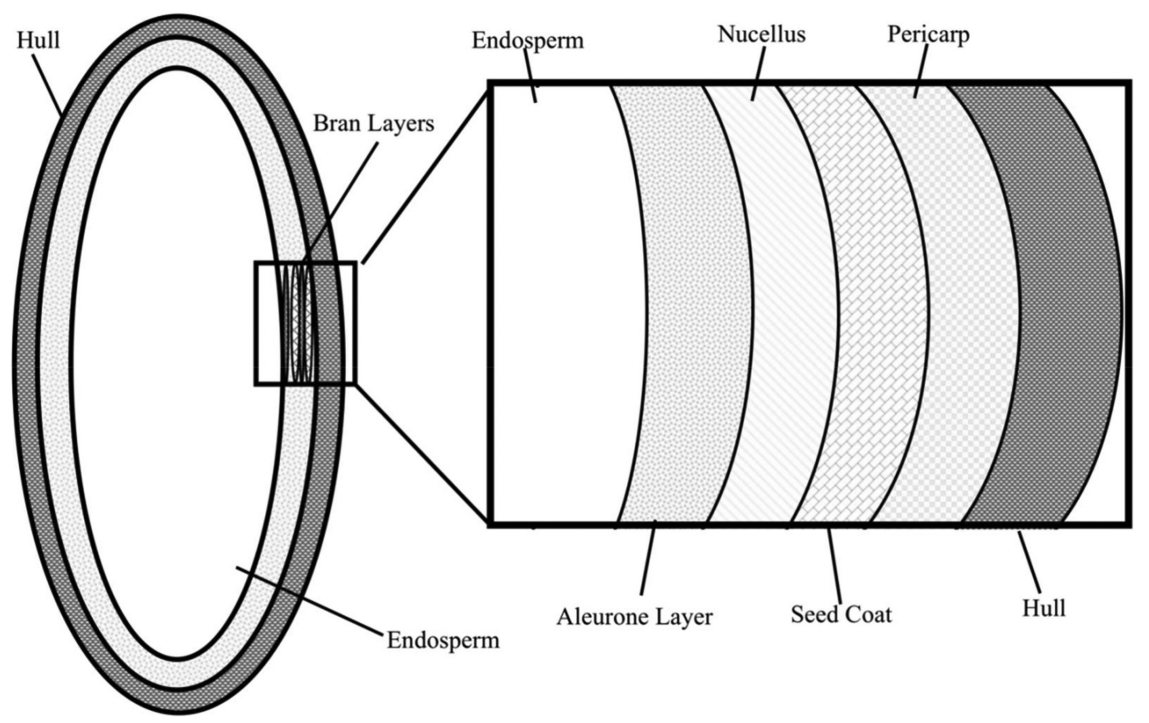

Fig. 1. Anatomical composition of the rice grain. The bran constitutes of several layers and it is where a large majority of the polyphenols reside in both soluble and insoluble forms. 
Table 1

Average ranges of total polyphenol composition of whole-grain non-pigmented and pigmented rice varieties.

\begin{tabular}{|c|c|c|c|c|}
\hline Compound & Rice variety & Soluble & Insoluble & References \\
\hline \multirow[t]{2}{*}{$\begin{array}{l}\text { Total phenolic acids }(\mathrm{mg} / 100 \mathrm{~g} \\
\text { DW) }\end{array}$} & Non-pigmented & $0.1-254$ & $1.64-484$ & $\begin{array}{l}\text { (Aguilar-Garcia et al., 2007; Deng et al., 2012; Irakli et al., 2012; } \\
\text { Vichapong et al., 2010; Zhu et al., 2010) }\end{array}$ \\
\hline & Pigmented & $38.1-2470$ & $2.53-401.6$ & $\begin{array}{l}\text { (Chung and Lee, 2003; Seo et al., 2013; Vichapong et al., 2010; Zhu } \\
\text { et al., 2010) }\end{array}$ \\
\hline \multirow[t]{2}{*}{$\begin{array}{l}\text { Total flavonoids (mg catechin/ } \\
100 \mathrm{~g} \mathrm{DW} \text { ) }\end{array}$} & Non-pigmented & $31-317$ & $0.6-24$ & $\begin{array}{l}\text { (Basu et al., 2012; Chung and Lee, 2003; Min et al., 2012; Vichapong } \\
\text { et al., 2010) }\end{array}$ \\
\hline & Pigmented & $1.15-4680$ & $1.66-337.0$ & $\begin{array}{l}\text { (Kong and Lee, 2010; Min et al., 2011; Mohanlal et al., 2013; } \\
\text { Vichapong et al., 2010) }\end{array}$ \\
\hline \multirow{2}{*}{$\begin{array}{l}\text { Total anthocyanins (mg C-3-G/ } \\
100 \mathrm{~g} \mathrm{DW})\end{array}$} & Non-pigmented & $2.0-3.26$ & ND & (Saikia et al., 2012; Sutharut and Sudarat, 2012) \\
\hline & Pigmented & $0.33-245.36$ & ND & (Sompong et al., 2011; Yodmanee et al., 2011) \\
\hline \multirow{2}{*}{$\begin{array}{l}\text { Total proanthocyanidins (mg } \\
\text { catechin/100 g DW) }\end{array}$} & Non-pigmented & 5.02 & ND & (Mohanlal et al., 2013) \\
\hline & Pigmented & $5.04-202$ & ND & (Chen et al., 2016; Finocchiaro et al., 2010; Min et al., 2012) \\
\hline
\end{tabular}

Non-pigmented = Brown rice varieties; Pigmented = coloured (black + purple + red) varieties. C-3-G, Cyanidin-3-Glucoside; DW, dry weight; ND, Not detected.

\section{Flavonoids}

There are limited studies that focus on the flavonoid content in rice (Sriseadka et al., 2012). Excluding anthocyanidins, seven flavonoids in rice have been quantified and confirmed. Tricin accounts for $77 \%$ of the total flavonoid content followed by luteolin (14\%), apigenin (6\%), quercetin (3\%), isorhamnetin (1\%), kaempferol $(<1 \%)$ and myricetin $(<1 \%)$ (Deng et al., 2013; Goufo and Trindade, 2014; Irakli et al., 2012). Other flavonoids have been identified in rice, however, confirmation of their existence and quantification in other rice varieties remains to be explored.

\section{Anthocyanins and proanthocyanidins}

Anthocyanins are glycosylated aglycones and are the primary pigments in coloured rice. About eighteen anthocyanins have been identified in rice, of which only four have been quantified (Goufo and Trindade, 2014). Among rice cultivars, the different forms of anthocyanins vary depending on bran colour and the fraction of the rice variety being analyzed. However, a large majority of studies report cyanidin-3-O- $\beta$-glucoside (C3G) (51-84\%) and peonidin-3$O$ - $\beta$-glucoside (P3G) (6-16\%) to be the major anthocyanin constituents of black/purple rice (Ichikawa et al., 2001; Shahidi and Ambigaipalan, 2015; Zhang et al., 2010). Proanthocyanidins like anthocyanidins are highly reactive to reactive oxygen species (ROS) and may have health promoting effects against diseases. In rice, catechin and epicatechin are the most abundant proanthocyanidins in the bran (21-47 mg/100 g) and husk (2.0-2.74 mg/100 g) of pigmented rice varieties (Goufo and Trindade, 2014). Furthermore, Chen et al. (2016), found a 4.3-fold variation in total proanthocyanidin content in the bran of thirty-two red and purple rice varieties. The study found no significant differences in proanthocyanidin content between the red $\left(18.64 \pm 7.06 \mathrm{mg} / \mathrm{g}^{-1}\right.$ bran) and purple $\left(22.58 \pm 1.55 \mathrm{mg} / \mathrm{g}^{-1}\right.$ bran $)$ brans. However, the study did find the purple varieties to have significantly higher total phenolic and total flavonoid contents compared to the red varieties. The study attributed the higher phenolic and flavonoid contents in the purple rice to potential anthocyanins residing in the bran.

\section{Bioavailability of rice-derived polyphenols}

The bioavailability of polyphenols is a new area of interest in polyphenol research. However, there are limited studies in humans demonstrating polyphenol metabolism, absolute bioavailability and the mechanisms contributing to potential therapeutic effects. The absorption and metabolism of polyphenols is largely dependent on their chemical structure, degree of glycosylation/ acylation, conjugation with other polyphenols, molecular size, degree of polymerization and solubility (Bravo, 1998). Polyphenol profiles generated from in vitro gastrointestinal digestion assays on rice have found digested cooked rice to have higher TPC compared to undigested cooked and raw rice. Ti et al. (2015), found digested cooked brown rice to have $54.1 \%$ more TPC compared to raw brown rice. Of particular interest, the study found bound ferulic acid was $112.5 \%$ higher in digested cooked brown rice compared to raw brown rice. However, only one brown rice variety was used, limiting the ability to compare cooking and in vitro digestive processes between different rice varieties.

Similar findings were seen by Salawu et al. (2016), where cooked digested rice had higher TPC compared to raw digested rice. In particular, the digested cooked Ofada brown rice variety contained $14 \%$ more total phenolics compared to digested raw Ofada rice. This study also included another brown rice variety called Gboko. The Gboko variety did not have a higher cooked digested TPC compared to the digest raw Gboko sample. Furthermore, this study did not specify the pericarp colour of the rice varieties. The study stated the rice varieties used were phenolicrich. These studies indicate that cooking and digestive processes may increase the bioavailability of rice-derived polyphenols. In particular, these studies suggest that the thermal cooking process weakens the cell wall of the rice grain, enabling a higher extractability of polyphenols in particular of bound polyphenols.

The bound fraction has been attributed to be the major contributor of polyphenols, whereby the bound phenolics may survive the upper gastrointestinal digestive conditions and be subjected to colonic gut microflora where the bulk of the bound polyphenols are released (Adom and Liu, 2002). Some studies highlight that depending on the sugar moiety, anthocyanins are significantly hydrolyzed by gut microflora by cleavage of the 3-glycosidic linkage where the aglycones rapidly degrade into phenolic acids and aldehydes (Kay et al., 2004; Keppler and Humpf, 2005). Furthermore, methoxyl derivatives such as syringic and vanillic acid undergo O-demethylation in the presence of intestinal microflora (Faria et al., 2014). Hence, microbiota cleavage may modify the antioxidant properties and intestinal absorption capabilities of the ingested parent polyphenol.

In contrast, studies have shown that polyphenols, particularly glucuronidated and methylated conjugate metabolites of anthocyanins retain their basic anthocyanin molecular structure in urine and plasma of adult men indicating that antioxidant activity may be retained (Kay et al., 2005). de Ferrars et al. (2014) found that 
anthocyanins were metabolized into an extensive range of metabolites with varying levels of kinetics in eight healthy males. The study found C3G degraded into protocatechuic acid and phloroglucinaldehyde. Interestingly, protocatechuic acid further degraded into 13 other metabolites including vanillic acid, ferulic acid and hippuric acid. The maximum serum concentration $\left(\mathrm{C}_{\max }\right)$ of C3G post consumption was $141 \mathrm{nM}$ at around $1.8 \mathrm{~h}$ post consumption. Protocatechuic acid had a $\mathrm{C}_{\max }$ of $146 \mathrm{nM}$ occurring 2-3 h later than C3G. Whilst the mechanism is not entirely clear, results of the study suggest that the anthocyanin C3G primarily undergoes spontaneous degradation to protocatechuic acid and phloroglucinaldehyde in the small intestine. The study reported that many metabolites did not return to baseline after the $48 \mathrm{~h}$ sampling period. Therefore, sampling time can be seen as a limitation to this study as it did not extend to an appropriate time to determine complete recovery of the metabolites. In conjunction, the study was also limited by the small sample size $(n=8)$. Other bioavailability studies have suggested the liver to be the site of post-absorbed anthocyanin metabolism, resulting in anthocyanin monoglucuronides (Kuntz et al., 2015).

The mechanisms behind polyphenols metabolism and absorption are still very much debated. Further detailed studies need to be conducted to determine the extent to which polyphenols are metabolized and the mechanisms surrounding direct absorption of ingested parent polyphenols and their metabolites with particular focus on coloured rice consumption.

\section{Mechanisms in obesity pathogenesis}

The mechanisms behind the pathogenesis of obesity have been extensively studied. Increased weight gain for a large majority of people is the result of high-fat diets (HFD) and high-sugar diets (HSD) in conjunction with physical inactivity. In adipocytes, excessive accumulation of intracellular triglycerides initiates lipotoxicity on mitochondria. Mitochondrial dysfunction has been associated in the pathogenesis of obesity and obesity-related diseases. In functional mitochondria, glucose is metabolized via the tricarboxylic acid cycle where electron donors are generated and enter the mitochondrial electron transport chain. However, with increased adiposity resultant of an unhealthy diet, the increased glucose load contributes to larger amounts of glucose being oxidized by the tricarboxylic acid cycle, resulting in the accrual of adenosine triphosphate (ATP) in the mitochondria. ATP accrual reduces adenosine diphosphate (ADP) levels, the efficiency of oxidative phosphorylation and mitochondrial uncoupling promoting the release of ROS and electron leakage (Savini et al., 2013).

Furthermore, the rapid increase in adipose tissue instigates recruitment and infiltration of macrophages resulting in localized low-grade inflammation (Yang et al., 2014). M1 macrophages contribute to the pro-inflamed status and are prevalent in obese individuals (Lumeng et al., 2007). Upon phagocytosis of oxidized low density lipoproteins (ox-LDL), M1 macrophages develop inflammatory foci called crown-like structures that are utilized to surround and remove dead adipocytes (Howe et al., 2013). However, the development of crown-like structures exposes M1 macrophages to saturated fatty acids (SFA's) resultant of obesityassociated lipolysis. Exposure to SFA's activates the Toll-Like 4 Receptor (TLR4) at the cell surface of the M1 macrophage and initiates the activation Nuclear Factor kappa-B (NF-кB) signalling pathway (Lee et al., 2003). Proinflammatory cytokines (such as Tumor Necrosis Factor- $\alpha$ (TNF- $\alpha$ ), Interleukin-6 (IL-6), inducible Nitric Oxide Synthase (iNOS)) and chemokines (monocyte chemotactic protein-1 (MCP1)) are secreted by M1 macrophages and contribute to obesity pathogenesis at a local and systemic level (Amano et al., 2014; Weisberg et al., 2003; Xu et al., 2003). Rice- derived polyphenols have been demonstrated to have antioxidant and anti-inflammatory potential in biological systems.

\section{Antioxidant properties of rice-derived polyphenols}

Rice-derived polyphenols have been shown to contain antioxidant potential. In particular, the antioxidant potential of flavonoids such as anthocyanins has been particularly attributed to their chemical structure. The level of hydroxylation on the $3^{\prime}$ and $4^{\prime}$ positions of the B-ring structure are fundamental determinants of the radical scavenging activity (Wang et al., 1997). However, there are limited studies demonstrating the antioxidant mechanisms of rice-derived polyphenols in biological systems. At the molecular level, black rice polyphenol extract (BRE) has been shown to protect supercoiled DNA from scission in peroxyl and hydroxyl radical environments (Hu et al., 2003). Furthermore, the study revealed that BRE suppressed the formation of ox-LDL in an in vitro oxidation assay and reduced nitric oxide production in macrophages without inducing cytotoxicity.

Sangkitikomol et al. (2010) screened the antioxidant activity of twenty-one commercially available red, black and black sticky rice varieties. The study found that the black-sticky rice had the highest antioxidant activity and also demonstrated to have DNA-protective characteristics in human mononuclear leukocytes in hydrogen peroxide-induced environments. Unfortunately, the study only investigated one black sticky rice variety out of the twenty-one screened rice varieties in their biological assay. The study chose the particular black sticky variety based on the antioxidant chemistry screening. However, chemistry-based antioxidant screening may not be a true representation of the antioxidant potential of ricederived polyphenols. Nam et al. (2006) found the thiocyanate method for determining in vitro lipid peroxidation was not a true representation of the antioxidant activity of pigmented rice varieties when compared to an in vitro biological peroxidation model. The study found selected pigmented rice varieties contained high antioxidant activity in the biological assay primarily displayed pro-oxidant activity in the thiocyanate assay. Nam et al. (2006) suggested that biological in vitro models may be more beneficial than in vitro chemistry assays in determining the antioxidant mechanism of action in biological systems. A comparison between pigmented varieties would be of interest to determine the biological antioxidant properties of rice-derived polyphenols to further develop therapeutic profiles.

Physiologically, BRE has been illustrated to increase plasma high density lipoprotein (HDL) cholesterol and upregulate SOD and catalase (CAT) activity in treated mice liver tissue (Chiang et al., 2006). In the same study, SOD and CAT activity was upregulated by 161.6\% and 73.4\% respectively in HepG2 cells. The study attributed their findings to the ability of anthocyanins, which are predominant in BRE, to upregulate radical scavenging enzymes (Fig. 2). Mohd Esa et al. (2013), demonstrated brown rice extract supplementation to hyperlipidaemic rabbits, increased SOD and glutathione peroxidase activity by $84.9 \%$ and $43.3 \%$ respectively. Furthermore, eight week supplementation of BRE in rats on a highfructose diet has been shown to significantly reduce blood oxidized-glutathione/glutathione ratio compared to high fructose diet controls (Guo et al., 2007). The study reported the BRE supplemented groups to having significantly lower levels of lipid peroxidation compared to the control group suggesting, the antioxidant properties associated with BRE (in particular, anthocyanins) may contribute to the inhibition of OS.

BRE has also been demonstrated to restore non-enzymatic antioxidant levels in rats with alcohol induced liver damage. In particular, serum glutathione levels were found to be significantly higher by $1.56 \mathrm{mg} / \mathrm{l}^{-1}$ in BRE supplemented rats compared to nonsupplemented alcohol-induced controls (Hou et al., 2010). Wang et al. (2007) conducted a double-blind, randomised trial where 


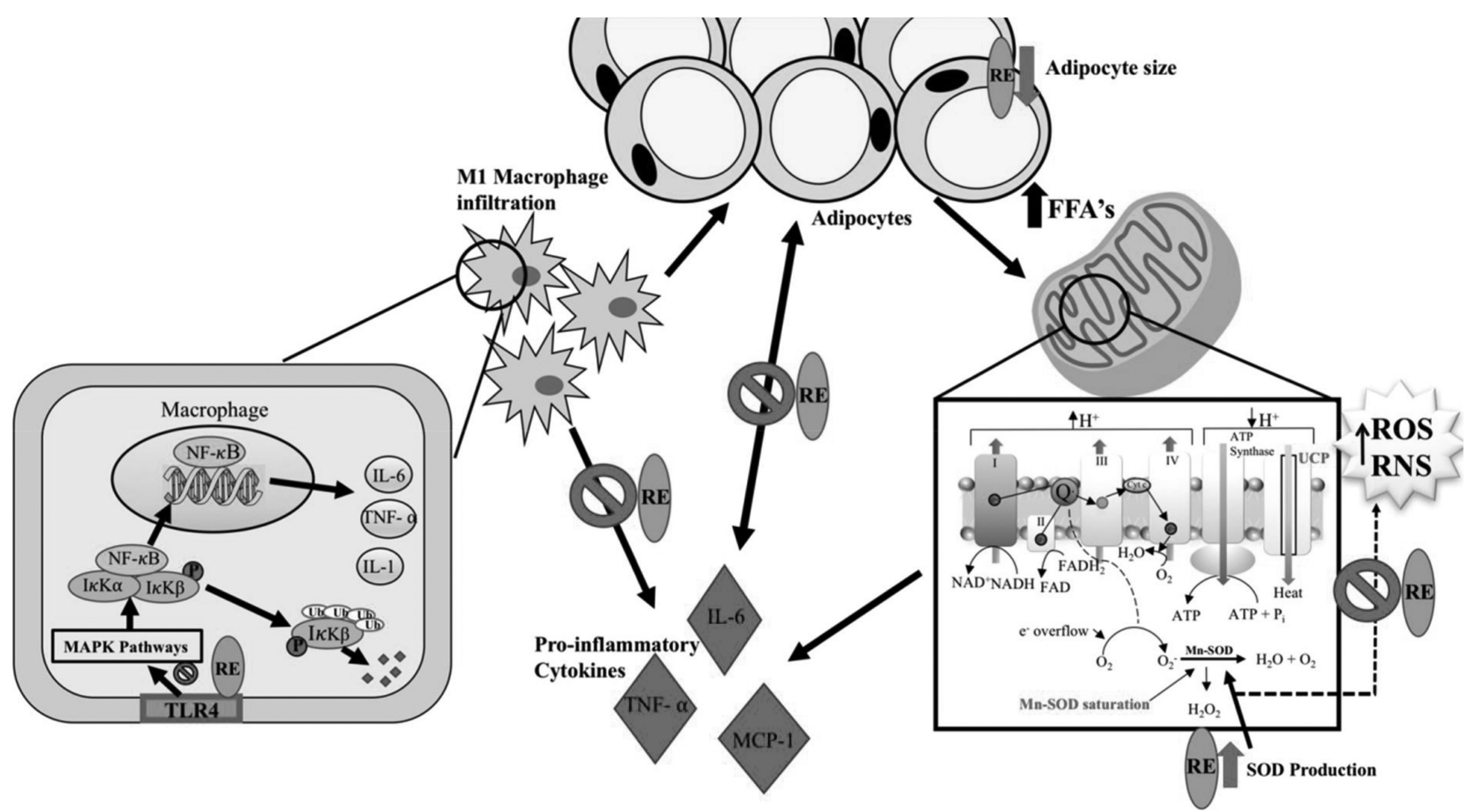

Fig. 2. The effect of rice-derived polyphenols on obesity pathways. Rice-derived polyphenol extracts (RE) have been shown to reduce adipocyte size and increase SOD production contributing to the reduction of ROS and RNS. Proinflammatory cytokines are also reduced in the presence of RE as RE have been shown to supress the secretion of proinflammatory cytokines in adipocytes and inhibit the MAPK pathways in macrophages.

$10 \mathrm{~g}$ of BRE was administered daily over six months to participants diagnosed with coronary heart disease. The study showed that participants who ingested the BRE had an increase in plasma total antioxidant capacity by $1.3 \mathrm{I}^{-1}$. The study did not find a significant increase in serum SOD levels indicating that anthocyanins may not upregulate the production of in vivo antioxidants but rather the direct intact absorption of anthocyanins may influence the increase in total antioxidant capacity by acting as a direct scavenger of ROS.

\section{Anti-inflammatory effects of rice-derived polyphenols}

Chronic inflammation has been associated in the obese and a major contributor to obesity-related diseases (Kushwaha, 2016). Rice-derived polyphenols have been demonstrated to have antiinflammatory potential. Candiracci et al. (2014), showed that supplementation of polyphenol extract derived from rice bran exerted anti-inflammatory properties by reducing the production of pro-inflammatory cytokines TNF- $\alpha$, IL- 6 and iNOS in the adipose tissue of obese Zucker rats. Adipocyte analysis determined that rice-bran polyphenol supplementation reduced adipocyte size in both abdominal and epididymal adipose tissue. Nevertheless, the study did not observe any significant differences in the final body weight of the rats and did not discuss the variety of the rice bran used to obtain the extracts. Similar findings with brown rice extracts have been demonstrated to reduce IL- $1 \alpha$ and TNF- $\alpha$ production cultured mouse macrophages (Okai et al., 2009).

Rice bran extracts have been shown to inhibit the release of prostaglandin E2 as well as modulate pro-inflammatory cytokine production in activated microglia (Bhatia et al., 2016). Similar findings were found by Min et al. (2010), where C3G and its metabolites, protocatechuic acid and cyanidin derived from black rice was found to attenuate the production of pro-inflammatory cytokines and their associated mediators in carrageenan-induced inflammation in BALB/c mice. Furthermore, the study found C3G and its metabolites downregulated nitric oxide synthase and cyclooxygenase-2 gene expression in the RAW 264.7 cells. Interestingly, C3G and its metabolites inhibited the phosphorylation of I $\mathrm{B}-\alpha$, the nuclear translocation of NF- $\kappa \mathrm{B}$ and the activation of mitogen-activated protein kinases (MAPK) which suggests that rice-derived polyphenols act as potent mediators of inflammation at the molecular level (Fig. 2). Shalini et al. (2015) observed similar characteristics where the flavonoid tricin isolated from red pigmented medicinal rice inhibited the signalling cascade of the MAPK pathways. Intraperitoneal injection of brown and black rice bran extract were found to reduce proinflammatory biomarkers in inflammatory mice models (Choi et al., 2010). In particular, the study found the expression of 5-LOX (5-lipooxygenase) was downregulated in mice treated with black rice bran. These findings suggest that flavonoids found in BRE may suppress the expression of 5-LOX and therefore effect downstream signalling such as intracellular adhesion molecule-1 expression reducing the infiltration of neutrophils into tissue (Choi et al., 2010).

Washing and cooking of black rice has been demonstrated to reduce the polyphenolic content and the antioxidant scavenging activity in in vitro antioxidant assays (Bhawamai et al., 2016). Interestingly, the study found cooked rice to have similar antiinflammatory effects when compared to raw rice polyphenol extract, suggesting that thermal cooking did not inhibit the antiinflammatory activity of black rice. Hence, rice-derived polyphenols may be targeting pathways of inflammation and hence may prove beneficial in overcoming the obesity epidemic.

Anti-dyslipidaemic properties of rice-derived polyphenols

Dyslipidaemia is generally termed as abnormal levels of lipids in the blood and has been significantly correlated to obesity. Biomarkers to establish blood lipid profiles include the total cholesterol, low density lipoprotein (LDL), HDL and triglycerides. Hyper-dyslipidaemia can be a consequence of increased adiposity 
associated with obesity can result in elevated levels in total cholesterol, LDL and triglycerides. In in vitro studies, black rice extract (BRE) has been shown to reduce lipid accumulation in C3H101/2 mesenchymal stem cells (MSC's) by suppressing adipocyte differentiation via downregulating key adipogenic transcription factors peroxisome proliferator activated-receptor$\gamma$, CCAAT-Enhancer Binding Protein- $\alpha$ and CCAAT-Enhancer Binding Protein- $\partial$ (Kim et al., 2016). The same study found that BRE was able to promote osteogenesis in MSC's via the upregulation of mRNA runt-related transcription factor 2 and alkaline phosphatase elevating intracellular calcium deposition. Similar observations was demonstrated by Jang et al. (2015), however, the study identified C3G and P3G as the most abundant polyphenols in their BRE. The study proposed that the anthocyanins potentially acted as regulators of the adipocyte/osteoblast axis in precursor cells as C3G and P3G inhibited lipid accumulation and induction of adipocyte transcription factors during adipocyte differentiation. Furthermore, the study also found that BRE prevents bone density loss in ovariectomized rats, indicating that BRE could be used as potential treatments for obesity and osteoporosis.

Anthocyanins in BRE, have been demonstrated to improve blood glucose levels (Prangthip et al., 2013), reduce serum triglyceride levels by 46\% (Xia et al., 2006) and to promote weight loss of 4.6\% (Yang et al., 2011) in rodents. A study by Jang et al. (2012), detailed BRE supplementation upregulated the expression of mRNA related to $\beta$ and $\omega$ fatty acid oxidation. Interestingly, even though fatty acid oxidation had increased in the presence of BRE, serum triglyceride levels and total cholesterol levels significantly decreased. BRE has been shown to improve plasma triglyceride levels in mice fed high fructose diets. Over an 8 week period, BRE was supplemented to rats on a high fructose diet (Guo et al., 2007).

Twelve-week supplementation of partially-abraded brown rice has been shown to attenuate weight gain and improve lipid metabolism in pre-diabetic overweight human subjects (Araki et al., 2017). In addition, brown rice bran supplementation has been shown to significantly reduce serum cholesterol levels and improve low density lipoprotein cholesterol to high density lipoprotein cholesterol ratios by $0.6 \mathrm{~mol} / \mathrm{mol}$ in moderately hyperlipidemic human subjects (Gerhardt and Gallo, 1998). Similar results were found by Qureshi et al. (2002), where human participants were supplemented with different brown rice bran fractions. The study found rice bran water solubles were effective in lowering serum glucose, total cholesterol, LDL-C and apolipoprotein B levels in both Type I and T2DM participants. The health promoting effects of the rice bran was attributed to the synergistic effect of multiple bioactive micro-components present in the rice bran (Table 2). In particular, the free-radical scavenging activities of ferulic acid, $\alpha$-lipoic acid and $p$-sinapic acid were suggested in the study to improve the complications associated with diabetes such as glycation, glycoxidation, atherosclerosis and hyperlipidemia.

\section{Conclusion and future directions}

In conclusion, the use of polyphenol-rich functional foods such as coloured rice could potentially act as a complementary therapeutic alternative to obesity and obesity-related diseases such as metabolic syndrome and cardiovascular disease. Studies to-date suggest that polyphenol supplementation into a HFD/HSD can modulate microbiota environments, regulate blood glucose, insulin and triglyceride levels as well as attenuate weight gain and visceral adipose tissue deposits via targeting inflammatory and OS pathways at the transcriptional and physiological level.

Rice is a major staple in more than half of the world's population, therefore integration of polyphenol-rich coloured rice varieties into global diets may prove beneficial in combating the obesity epidemic. Future work in identifying the synergistic effects of rice-derived polyphenols is required, specifically investigating the consumption of wholegrain rice and its effect in-vivo may

Table 2

Anti-dyslipidaemic potential of polyphenols derived from pigmented whole-grain rice in humans.

\begin{tabular}{|c|c|c|c|c|}
\hline Reference diet & Target group & Study design and intervention & Effects & Reference \\
\hline Brown rice bran & Healthy normal & $\begin{array}{l}\text { Participants consumed } 84 \mathrm{~g} \text { of rice bran/day } \\
\text { for } 6 \text { weeks in a randomised double blinded } \\
\text { trial }\end{array}$ & $\begin{array}{l}\uparrow \text { Triglycerides } \\
\downarrow \text { Total Cholesterol } \\
\downarrow \text { LDL } \\
\uparrow \text { HDL }\end{array}$ & (Gerhardt and Gallo, 1998) \\
\hline Stabilised brown rice bran & Clinically diagnosed T2DM & $\begin{array}{l}\text { Participants consumed stabilised rice bran, } \\
\text { rice bran water solubles or rice bran fibre } \\
\text { concentrates for } 60 \text { days for each rice bran } \\
\text { fraction with a } 30 \text {-day washout period } \\
\text { between each fraction }\end{array}$ & $\begin{array}{l}\downarrow \text { Triglycerides } \\
\downarrow \text { Total Cholesterol } \\
\downarrow \text { LDL } \\
=\text { HDL }\end{array}$ & (Qureshi et al., 2002) \\
\hline Stabilised brown rice bran & T2DM & $\begin{array}{l}\text { Participants were divided into two groups } \\
\text { where one group consumed } 20 \mathrm{~g} \text { of rice bran } \\
\text { daily compared to a placebo group for } 12 \\
\text { weeks }\end{array}$ & $\begin{array}{l}\downarrow \text { Triglycerides } \\
\downarrow \text { Total Cholesterol } \\
\downarrow \text { LDL } \\
=\text { HDL }\end{array}$ & (Cheng et al., 2010) \\
\hline Black rice pigment fraction & $\begin{array}{l}\text { Clinically diagnosed coronary } \\
\text { heart disease }\end{array}$ & $\begin{array}{l}\text { Participants consumed } 10 \mathrm{~g} \text { of black rice } \\
\text { pigment fraction daily for } 6 \text { months }\end{array}$ & $\begin{array}{l}\downarrow \text { Triglycerides } \\
\downarrow \text { Total Cholesterol } \\
\downarrow \text { LDL } \\
=\mathrm{HDL}\end{array}$ & (Wang et al., 2007) \\
\hline Pre-germinated brown rice & $\begin{array}{l}\text { Impaired glucose tolerant } \\
\text { females }\end{array}$ & $\begin{array}{l}\text { Participants were gradually weaned onto a } \\
\text { pre-germinated brown rice diet for } 4 \text { months } \\
\text { as a staple food. }\end{array}$ & $\begin{array}{l}\downarrow \text { Triglycerides } \\
\downarrow \text { Total Cholesterol } \\
\downarrow \text { LDL } \\
\uparrow \text { HDL }\end{array}$ & (Nhung et al., 2016) \\
\hline Black rice bran & Overweight/obese & $\begin{array}{l}\text { Participants consumed snack bars containing } \\
\text { pigmented rice bran for } 8 \text { weeks whilst on a } \\
25 \% \text { calories restricted diet }\end{array}$ & $\begin{array}{l}\uparrow \text { Triglycerides } \\
\downarrow \text { Total Cholesterol } \\
\downarrow \text { LDL } \\
\downarrow \text { HDL }\end{array}$ & (Hongu et al., 2014) \\
\hline
\end{tabular}

HDL, High density lipoprotein; LDL, Low density lipoprotein; T2DM, Type II diabetes mellitus. $\uparrow$, Increase; $\downarrow$, Decrease; =, No change. 
demonstrate an alternative and possibly a more pronounced effect than the consumption of a purified polyphenol on its own.

\section{Conflict of interests}

The authors declare no conflict of interests. All authors have read and approved the final manuscript.

\section{Acknowledgements}

Esther Callcott is a recipient of the Australian Research Council Industrial Transformation Training Centre for Functional Grains scholarship through Charles Sturt University.

\section{References}

Adom, K.K., Liu, R.H., 2002. Antioxidant activity of grains. J. Agric. Food Chem. 50, 6182-6187.

Aguilar-Garcia, C., Gavino, G., Baragaño-Mosqueda, M., Hevia, P., Gavino, V.C., 2007. Correlation of tocopherol, tocotrienol, $\gamma$-oryzanol and total polyphenol content in rice bran with different antioxidant capacity assays. Food Chem. 102, 12281232.

Amano, S.U., Cohen, J.L., Vangala, P., Tencerova, M., Nicoloro, S.M., Yawe, C., et al., 2014. Local proliferation of macrophages contributes to obesity-associated adipose tissue Inflammation. Cell Met. 19, 162-171.

Araki, R., Ushio, R., Fujie, K., Ueyama, Y., Suzuki, H., Nakata, Y., Hashimoto, K., 2017. Effect of partially-abraded brown rice consumption on body weight and the indicators of glucose and lipid metabolism in pre-diabetic adults: a randomized controlled trial. Clin. Nutr. ESPEN. 19, 9-15.

Balasundram, N., Sundram, K., Samman, S., 2006. Phenolic compounds in plants and agri-industrial by-products: antioxidant activity occurrence, and potential uses. Food Chem. 99, 191-203.

Basu, S., Roychoudhury, A., Sanyal, S., Sengupta, D.N., 2012. Carbohydrate content and antioxidative potential of the seed of three edible indica rice (Oryza sativa L.) cultivars. Indian J. Biochem. Biophys. 49, 115-123.

Bhatia, H.S., Baron, J., Hagl, S., Eckert, G.P., Fiebich, B.L., 2016. Rice bran derivatives alleviate microglia activation: possible involvement of MAPK pathway. J. Neuroinflammation 13, 148-164.

Bhawamai, S., Lin, S.H., Hou, Y.Y., Chen, Y.H., 2016. Thermal cooking changes the profile of phenolic compounds, but does not attenuate the anti-inflammatory activities of black rice. Food Nutr. Res. 60, 32941-32950.

Bravo, L., 1998. Polyphenols: chemistry, dietary sources, metabolism, and nutritional significance. Nutr. Rev. 56, 317-333.

Butsat, S., Siriamornpun, S., 2010. Antioxidant capacities and phenolic compounds of the husk: bran and endosperm of Thai rice. Food Chem. 119, 606-613.

Candiracci, M., Justo, M.L., Castaño, A., Rodriguez-Rodriguez, R., Herrera, M.D., 2014. Rice bran enzymatic extract-supplemented diets modulate adipose tissue inflammation markers in Zucker rats. Nutrition 30, 466-472.

Chen, H., Siebenmorgen, T., Griffin, K., 1998. Quality characteristics of long-grain rice milled in two commercial systems. Cereal Chem. 75, 560-565.

Chen, M.-H., McClung, A.M., Bergman, C.J., 2016. Concentrations of oligomers and polymers of proanthocyanidins in red and purple rice bran and their relationships to total phenolics flavonoids, antioxidant capacity and whole grain color. Food Chem. 208, 279-287.

Cheng, H.H., Huang, H.Y., Chen, Y.Y., Huang, C.L., Chang, C.J., Chen, H.L., Lai, M.H., 2010. Ameliorative effects of stabilized rice bran on type 2 diabetes patients. Ann. Nutr. Metab. 56, 45-51.

Chiang, A., Wu, H.-L., Yeh, H.-I., Chu, C.-S., Lin, H.-C., Lee, W.-C., 2006. Antioxidant effects of black rice extract through the induction of superoxide dismutase and catalase activities. Lipids 41, 797-803.

Choi, S.P., Kim, S.P., Kang, M.Y., Nam, S.H., Friedman, M., 2010. Protective effects of black rice bran against chemically-induced inflammation of mouse skin. J. Agric. Food Chem. 58, 10007-10015.

Chung, Y.A., Lee, J.K., 2003. Antioxidative properties of phenolic compounds extracted from black rice. J. Korean. Soc. Horti. Sci. 32, 948-951.

Corke, H., 2015. Grain: morphology of internal structure, In: Wrigley, C.W., Corke, H., Seetharaman, K., Faubion, J. (Eds.), Encyclopedia of Food Grains. 2nd ed. Elsevier, Oxford, pp. 41-49.

Deng, G.-F., Xu, X.-R., Guo, Y.-J., Xia, E.-Q., Li, S., Wu, S., et al., 2012. Determination of antioxidant property and their lipophilic and hydrophilic phenolic contents in cereal grains. J. Funct. Foods 4, 906-914.

Deng, G.-F., Xu, X.-R., Zhang, Y., Li, D., Gan, R.-Y., Li, H.-B., 2013. Phenolic compounds and bioactivities of pigmented rice. Crit. Rev. Food Sci. Nutr. 53, 296-306.

Emdin, C.A., Khera, A.V., Natarajan, P., Klarin, D., Zekavat, S.M., Hsiao, A.J., Kathiresan, S., 2017. Genetic association of waist-to-hip ratio with cardiometabolic traits, type 2 Diabetes, and coronary heart disease. JAMA 317, 626-634.

Faria, A., Fernandes, I., Norberto, S., Mateus, N., Calhau, C., 2014. Interplay between anthocyanins and gut microbiota. J. Agric. Food Chem. 62, 6898-6902.

Finocchiaro, F., Ferrari, B., Gianinetti, A., 2010. A study of biodiversity of flavonoid content in the rice caryopsis evidencing simultaneous accumulation of anthocyanins and proanthocyanidins in a black-grained genotype. J. Cereal. Sci. $51,28-34$.

Gerhardt, A.L., Gallo, N.B., 1998. Full-fat rice bran and oat bran similarly reduce hypercholesterolemia in humans. J. Nutr. 128, 865-869.

Goufo, P., Trindade, H., 2014. Rice antioxidants: phenolic acids, flavonoids, anthocyanins, proanthocyanidins, tocopherols, tocotrienols, $\gamma$-oryzanol, and phytic acid. Food. Sci. Nutr. 2, 75-104.

Goufo, P., Trindade, H., 2017. Factors influencing antioxidant compounds in rice. Crit. Rev. Food Sci. Nutr. 57 (5), 893-922.

Goufo, P., Pereira, J., Figueiredo, N., Oliveira, M.B.P., Carranca, C., Rosa, E.A., Trindade, H., 2014. Effect of elevated carbon dioxide (CO2) on phenolic acids, flavonoids, tocopherols, tocotrienols, $\gamma$-oryzanol and antioxidant capacities of rice (Oryza sativa L.). J. Cereal. Sci. 59, 15-24.

Guh, D., Zhang, W., Bansback, N., Amarsi, Z., Birmingham, C.L., Anis, A., 2009. The incidence of co-morbidities related to obesity and overweight: a systematic review and meta-analysis. BMC Public Health 9, 88-108.

Guo, H., Ling, W., Wang, Q., Liu, C., Hu, Y., Xia, M., et al., 2007. Effect of anthocyaninrich extract from black rice (Oryza sativa L. indica) on hyperlipidemia and insulin resistance in fructose-fed rats. Plant Foods Hum. Nutr. 62, 1-6.

Hongu, N., Kitts, D.D., Zawistowski, J., Dossett, C.M., Kopec, A., Pope, B.T., Buchowski, M.S., 2014. Pigmented rice bran and plant sterol combination reduces serum lipids in overweight and obese adults. J. Am. Coll. Nutr. 33, 231-238.

Hou, Z., Qin, P., Ren, G., 2010. Effect of anthocyanin-rich extract from black rice (Oryza sativa L. japonica) on chronically alcohol-induced liver damage in rats. J. Agric. Food Chem. 58, 3191-3196.

Howe, L.R., Subbaramaiah, K., Hudis, C.A., Dannenberg, A.J., 2013. Molecular pathways: adipose inflammation as a mediator of obesity-associated cancer. Clin. Cancer. Res. 19, 6074-6083.

Hu, C., Zawistowski, J., Ling, W., Kitts, D.D., 2003. Black rice (Oryza sativa L. indica) pigmented fraction suppresses both reactive oxygen species and nitric oxide in chemical and biological model systems. J. Agric. Food Chem. 51, 5271-5277.

Huang, C.J., McAllister, M.J., Slusher, A.L., Webb, H.E., Mock, J.T., Acevedo, E.O., 2015 Obesity-related oxidative stress: the impact of physical activity and diet manipulation. Sports. Med-Open 1, 32-44.

Huang, P.L., 2009. A comprehensive definition for metabolic syndrome. Dis. Mod. Mech. 2, 231-237.

Ichikawa, H., Ichiyanagi, T., Xu, B., Yoshii, Y., Nakajima, M., Konishi, T., 2001. Antioxidant activity of anthocyanin extract from purple black rice. J. Med. Food 4, 211-218.

Irakli, M.N., Samanidou, V.F., Biliaderis, C.G., Papadoyannis, I.N., 2012. Simultaneous determination of phenolic acids and flavonoids in rice using solid-phase extraction and RP-HPLC with photodiode array detection. J. Sep. Sci. 35, 16031611.

Jang, H.-H., Park, M.-Y., Kim, H.-W., Lee, Y.-M., Hwang, K.-A., Park, J.-H., et al., 2012. Black rice (Oryza sativa L.) extract attenuates hepatic steatosis in C57BL/6 J mice fed a high-fat diet via fatty acid oxidation. Nutr. Metab. 9, 27-38.

Jang, W.-S., Seo, C.-R., Jang, H.H., Song, N.-J., Kim, J.-K., Ahn, J.-Y., et al., 2015. Black rice (Oryza sativa L.) extracts induce osteoblast differentiation and protect against bone loss in ovariectomized rats. Food Funct. 6, 264-274.

Kakkar, A.K., Dahiya, N., 2015. Drug treatment of obesity: current status and future prospects. Eur. J. Intern. Med. 26, 89-94.

Kay, C.D., Mazza, G., Holub, B.J., Wang, J., 2004. Anthocyanin metabolites in human urine and serum. Br. J. Nutr. 91, 933-942.

Kay, C.D., Mazza, G., Holub, B.J., 2005. Anthocyanins exist in the circulation primarily as metabolites in adult men. J. Nutr. 135, 2582-2588.

Kealey, L.M., Clampett, W.S., 2000. Production of Quality Rice in South Eastern Australia. Rural Industries Research and Development Corporation, Kingston, ACT.

Keaney, J.F., Larson, M.G., Vasan, R.S., Wilson, P.W., Lipinska, I., Corey, D., et al., 2003. Obesity and systemic oxidative stress. Atertio. Thromb. Vasc. Biol. 23, 434-439.

Keppler, K., Humpf, H.-U., 2005. Metabolism of anthocyanins and their phenolic degradation products by the intestinal microflora. Bioorg. Med. Chem. 13, 51955205.

Kim, S.Y., Kim, Y.J., An, Y.J., Lee, H.J., Lee, S.H., Kim, J.B., et al., 2016. Black rice (Oryza sativa, heukmi) extracts stimulate osteogenesis but inhibit adipogenesis in mesenchymal C3H10T1/2 cells. J. Food Biochem. 40, 235-247.

Kong, S., Lee, J., 2010. Antioxidants in milling fractions of black rice cultivars. Food Chem. 120, 278-281.

Kuntz, S., Rudloff, S., Asseburg, H., Borsch, C., Fröhling, B., Unger, F., et al., 2015 Uptake and bioavailability of anthocyanins and phenolic acids from grape/ blueberry juice and smoothie in vitro and in vivo. Br. J. Nutr. 113, 1044-1055.

Kushwaha, U.K.S. (Ed.), 2016. Black Rice: Research, History and Development. Springer International Publishing, Cham, pp. 155-184.

Lee, J.Y., Ye, J., Gao, Z., Youn, H.S., Lee, W.H., Zhao, L., et al., 2003. Reciprocal modulation of toll-like receptor-4 signalling pathways involving MyD88 and phosphatidylinositol 3-kinase/AKT by saturated and polyunsaturated fatty acids. J. Biol. Chem. 278, 37041-37051.

Lumeng, C.N., Bodzin, J.L., Saltiel, A.R., 2007. Obesity induces a phenotypic switch in adipose tissue macrophage polarization. J. Clin. Invest. 117, 175-184.

Min, S.-W., Ryu, S.-N., Kim, D.-H., 2010. Anti-inflammatory effects of black rice, cyanidin-3-O- $\beta$-d-glycoside, and its metabolites, cyanidin and protocatechuic acid. Int. Immunopharmacol. 10, 959-966.

Min, B., McClung, A.M., Chen, M.-H., 2011. Phytochemicals and antioxidant capacities in rice brans of different color. J. Food Sci. 76, C117-C126.

Min, B., Gu, L., McClung, A.M., Bergman, C.J., Chen, M.-H., 2012. Free and bound total phenolic concentrations antioxidant capacities, and profiles of 
proanthocyanidins and anthocyanins in whole grain rice (Oryza sativa L) of different bran colours. Food Chem. 133, 715-722.

Mohanlal, S., Parvathy, R., Shalini, V., Mohanan, R., Helen, A., Jayalekshmy, A., 2013. Chemical indices, antioxidant activity and anti-inflammatory effect of extracts of the medicinal rice njavara and staple varieties: a comparative study. J. Food Biochem. 37, 369-380.

Mohanty, S., 2013. Trends in global rice consumption. Rice Today 12, 44-45.

Mohd Esa, N., Abdul Kadir, K.-K., Amom, Z., Azlan, A., 2013. Antioxidant activity of white rice, brown rice and germinated brown rice (in vivo and in vitro) and the effects on lipid peroxidation and liver enzymes in hyperlipidaemic rabbits. Food Chem. 141 (2), 1306-1312.

Nam, S.H., Choi, S.P., Kang, M.Y., Koh, H.J., Kozukue, N., Friedman, M., 2006. Antioxidative activities of bran extracts from twenty one pigmented rice cultivars. Food Chem. 94, 613-620.

Nhung, B.T., Tuyen, L.D., Linh, V.A., Anh, N.D., Nga, T.T., Thuc, V.T., et al., 2016. Rice bran extract reduces the risk of atherosclerosis in post-menopausal Vietnamese women. J. Nutr. Sci. Vitaminol. (Tokyo) 62, 295-302.

Okai, Y., Okada, T., Higashi-Okai, K., Kasahara, E., Inoue, M., Yamashita, U., 2009. Immunomodulating activities in bran extracts of Japanese red, black and brown rices. J. UOEH 31, 231-242.

Prangthip, P., Surasiang, R., Charoensiri, R., Leardkamolkarn, V., Komindr, S., Yamborisut, U., et al., 2013. Amelioration of hyperglycemia, hyperlipidemia oxidative stress and inflammation in steptozotocin-induced diabetic rats fed a high fat diet by riceberry supplement. J. Funct. Foods 5, 195-203.

Qureshi, A.A., Sami, S.A., Khan, F.A., 2002. Effects of stabilized rice bran, it's soluble and fiber fractions on blood glucose levels and serum lipid parameters in humans with diabetes mellitus Types I and II. J. Nutr. Biochem. 13, 175-187.

Rippe, J.M., Crossley, S., Ringer, R., 1998. Obesity as a chronic disease: modern medical and lifestyle management. J. Am. Diet. Assoc. 98, S9-S15.

Saikia, S., Dutta, H., Saikia, D., Mahanta, C.L., 2012. Quality characterisation and estimation of phytochemicals content and antioxidant capacity of aromatic pigmented and non-pigmented rice varieties. Food Res. Int. 46, 334-340.

Salawu, S.O., Alao, O.F., Faloye, O.F., Akindahunsi, A.A., Boligon, A.A., Athayde, M.L. 2016. Antioxidant potential of phenolic-rich two varieties of Nigerian local rice and their anti-cholinesterase activities after in vitro digestion. Nutr. Food Sci. 46, 171-189.

Salvado, M.J., Casanova, E., Fernandez-Iglesias, A., Arola, L., Blade, C., 2015. Roles of proanthocyanidin rich extracts in obesity. Food Funct. 6, 1053-1071.

Sangkitikomol, W., Tencomnao, T., Rocejanasaroj, A., 2010. Antioxidant effects of anthocyanins-rich extract from black sticky rice on human erythrocytes and mononuclear leukocytes. Afr. J. Biotech 9, 8222-8229.

Santhakumar, A., Bulmer, A., Singh, I., 2014. A review of the mechanisms and effectiveness of dietary polyphenols in reducing oxidative stress and thrombotic risk. J. Hum. Nutr. Diet. 27, 1-21.

Savini, I., Catani, M.V., Evangelista, D., Gasperi, V., Avigliano, L., 2013. Obesityassociated oxidative stress: strategies finalized to improve redox state. Int. J. Mol. Sci. 14, 10497-10538.

Seo, W.D., Kim, J.Y., Song, Y.-C., Cho, J.-H., Jang, K.C., Han, S.-I., et al., 2013. Comparative analysis of physicochemicals and antioxidative properties in new red rice (Oryza sativa L. cv. Gunganghongmi). J. Crop. Sci. Biotechnol. 16, 63-68.

Shahidi, F., Ambigaipalan, P., 2015. Phenolics and polyphenolics in foods, beverages and spices: antioxidant activity and health effects -a review. J. Funct. Foods 18 , 820-897.

Shalini, V., Jayalekshmi, A., Helen, A., 2015. Mechanism of anti-inflammatory effect of tricin, a flavonoid isolated from Njavara rice bran in LPS induced hPBMCs and carrageenan induced rats. Mol. Immunol. 66, 229-239.

Sompong, R., Siebenhandl-Ehn, S., Linsberger-Martin, G., Berghofer, E., 2011. Physicochemical and antioxidative properties of red and black rice varieties from Thailand, China and Sri Lanka. Food Chem. 124, 132-140.
Sriseadka, T., Wongpornchai, S., Rayanakorn, M., 2012. Quantification of flavonoids in black rice by liquid chromatography-negative electrospray ionization tandem mass spectrometry. J. Agric. Food Chem. 60, 11723-11732.

Sutharut, J., Sudarat, J., 2012. Total anthocyanin content and antioxidant activity of germinated colored rice. Int. Food. Res. J. 19, 215-221.

Ti, H., Zhang, R., Li, Q., Wei, Z., Zhang, M., 2015. Effects of cooking and in vitro digestion of rice on phenolic profiles and antioxidant activity. Food Res. Int. 76 (Part 3), 813-820.

Tuncel, N.B., Yılmaz, N., 2011. Gamma-oryzanol content, phenolic acid profiles and antioxidant activity of rice milling fractions. Eur. Food Res. Technol. 233, 577585.

Vichapong, J., Sookserm, M., Srijesdaruk, V., Swatsitang, P., Srijaranai, S., 2010. High performance liquid chromatographic analysis of phenolic compounds and their antioxidant activities in rice varieties. LWT-Food. Sci. Tech. 43, 1325-1330.

Visioli, F., 2016. Nutraceuticals in the treatment of metabolic syndrome. In: Mahabir S., Pathak, Y. (Eds.), Nutraceuticals and Health: Review of Human Evidence. Taylor \& Francis, Boca Raton, FL, pp. 191-197.

World Health Organisation (WHO), 2015. Obesity and overweight factsheet No. 311. [online] [cit. 2017-08-16]. Available from: http://www.wpro.who.int/ mediacentre/factsheets/obesity/en/.

Wang, H., Cao, G., Prior, R.L., 1997. Oxygen radical absorbing capacity of anthocyanins. J. Agric. Food Chem. 45, 304-309.

Wang, Q., Han, P., Zhang, M., Xia, M., Zhu, H., Ma, J., et al., 2007. Supplementation of black rice pigment fraction improves antioxidant and anti-inflammatory status in patients with coronary heart disease. Asia Pac. J. Clin. Nutr. 16, 295-301.

Weisberg, S.P., McCann, D., Desai, M., Rosenbaum, M., Leibel, R.L., Ferrante Jr., A.W., 2003. Obesity is associated with macrophage accumulation in adipose tissue. J. Clin. Invest. 112, 1796-1808.

Wrolstad, R.E., Acree, T.E., Decker, E.A., Penner, M.H., Reid, D.S., Schwartz, S.J., et al. 2005. Anthocyanins -handbook of Food Analytical Chemistry. John Wiley \& Sons, Inc., New Jersey, pp. 5-69.

Xia, X., Ling, W., Ma, J., Xia, M., Hou, M., Wang, Q., et al., 2006. An anthocyanin-rich extract from black rice enhances atherosclerotic plaque stabilization in apolipoprotein e-deficient mice. J. Nutr. 136, 2220-2225.

Xu, H., Barnes, G.T., Yang, Q., Tan, G., Yang, D., Chou, C.J., et al., 2003. Chronic inflammation in fat plays a crucial role in the development of obesity-related insulin resistance. J. Clin. Invest. 112, 1821.

Yang, Y., Andrews, M.C., Hu, Y., Wang, D., Qin, Y., Zhu, Y., et al., 2011. Anthocyanin extract from black rice significantly ameliorates platelet hyperactivity and hypertriglyceridemia in dyslipidemic rats induced by high fat diets. J. Agric. Food Chem. 59, 6759-6764.

Yang, J., Zhang, L., Yu, C., Yang, X.-F., Wang, H., 2014. Monocyte and macrophage differentiation: circulation inflammatory monocyte as biomarker for inflammatory diseases. Biomark. Res. 2, 1-9.

Yodmanee, S., Karrila, T., Pakdeechanuan, P., 2011. Physical, chemical and antioxidant properties of pigmented rice grown in Southern Thailand. Int. Food. Res. J. 18, 901-906.

Zhang, M.W., Zhang, R.F., Zhang, F.X., Liu, R.H., 2010. Phenolic profiles and antioxidant activity of black rice bran of different commercially available Varieties. J. Agric. Food Chem. 58, 7580-7587.

Zhou, Z., Robards, K., Helliwell, S., Blanchard, C., 2004. The distribution of phenolic acids in rice. Food Chem. 87, 401-406.

Zhu, F., Cai, Y.-Z., Bao, J., Corke, H., 2010. Effect of $\gamma$-irradiation on phenolic compounds in rice grain. Food Chem. 120, 74-77.

de Ferrars, R.M., Czank, C., Zhang, Q., Botting, N.P., Kroon, P.A., Cassidy, A., Kay, C.D., 2014. The pharmacokinetics of anthocyanins and their metabolites in humans. Br. J. Pharmacol. 171, 3268-3282.

de Mira, N.V.M., Massaretto, I.L., Pascual, C.D.S.C.I., Lanfer, M.U.M., 2009. Comparative study of phenolic compounds in different Brazilian rice (Oryza sativa L.) genotypes. J. Food Compost. Anal. 22, 405-409. 